\section{THU0230 PERFORMANCE OF AN ONLINE SELF-REFERRAL QUESTIONNAIRE COMPARED TO A PHYSICIAN-BASED REFERRAL APPROACH TO IDENTIFY PATIENTS WITH A HIGH PROBABILITY OF AXIAL SPONDYLOARTHRITIS: RESULTS FROM THE OPTIREF STUDY}

F. Proft ${ }^{1}$, L. Spiller ${ }^{1}$, M. Protopopov ${ }^{1}$, M. Schmidt ${ }^{1}$, V. Rios Rodriguez ${ }^{1}$, B. Muche ${ }^{1}$, J. Rademacher ${ }^{1}$, S. Lüders ${ }^{1}$, A.-K. Weber ${ }^{1}$, I. Spiller ${ }^{1}$, J. Sieper ${ }^{1}$, D. Poddubny ${ }^{1,2}$ ${ }^{1}$ Charité - Universitätsmedizin Berlin; ${ }^{2}$ German Rheumatism Research Centre, Berlin, Germany

Background: The diagnostic delay in axial spondyloarthritis (axSpA) has been reported to be 9 years and still remains unacceptably high. One of the major reasons for this delay is a late referral of patients with suspicion of axSpA by primary care $(\mathrm{PC})$ physicians dealing with patients with chronic back pain (CBP). Physician-based referral programs have performed well in recognition of patients with high probability of axSpA among CBP patients. However, there is still an unmet need for patients who do not receive a referral to a rheumatologists because of lack of awareness on PC level.

Objectives: To develop and evaluate an online self-referral tool for CBP patients and suspicion of axSpA.

Methods: Patients with CBP were included in the Identification of the Optimal Referral Strategy for Early Diagnosis of Axial Spondyloarthritis (OptiRef) Study and assessed by a rheumatologist if they either 1)were referred by a physician using the Berlin referral tool (CBP $>3$ months and CBP onset $<45$ years of age +at least 1 of the following 3 parameters: inflammatory back pain (IBP), HLAB27 positivity, sacroilitis on imaging), or 2)completed an online referral tool (www. bechterew-check.de) and indicated the presence of $\mathrm{CBP}>3$ months with $\mathrm{CBP}$ onset $<45$ years of age +at least 1 additional SpA parameter (IBPsymptoms, good response to NSAID's, peripheral symptoms suggestive of arthritis/enthesitis, HLA-B27 positivity, elevated CRP, psoriasis, inflammatory bowel disease, uveitis, familyhistory). Rheumatologist then performed a structured assessment of SpA features and made the diagnosis of axSpA/non-axSpA.

Results: A total of 339 patients were included in the study: 162 patients $(47.8 \%)$ were referred by a physician and $177(52.2 \%)$ entered the study via the online self-referral tool. A total of 60 patients (37\%) in the physician-referral group and 33 $(18.6 \%)$ in the self-referral group were finally diagnosed with axSpA $(p<0.001)$. The main patient characteristics are shown in table1. Patients who were included via the online referral tool had a longer symptom duration, were more often females, less often HLA-B27 positive and had less often elevated CRP as compared to physician-referred patients. Furthermore, the physician global assessment of disease activity done by a rheumatologist was significantly lower in the self-referred group. In patients diagnosed with axSpA there were no significant differences concerning demographics, clinical features or disease activity parameters between the two groups, except of HLA-B27, which was significantly more often positive in subjects referred by a physician $(p<0.001)$.

Abstract THU0230 - Table 1. Characteristics of patients with CBP and suspicion of axSpA referred by a physician or by a self-referral online tool.

\begin{tabular}{|c|c|c|c|}
\hline Characteristics & $\begin{array}{c}\text { Referral by } \\
\text { a physician } \\
\mathrm{N}=162\end{array}$ & $\begin{array}{c}\text { Self- } \\
\text { referral } \\
\mathrm{N}=177\end{array}$ & p-value* \\
\hline Diagnosis of axSpA, $n(\%)$ & $60(37.0 \%)$ & $33(18.6 \%)$ & $<0.001$ \\
\hline Age, years (mean $\pm S D$ ) & $37.3 \pm 11.8$ & $36.6 \pm 9.2$ & 0.99 \\
\hline Female sex, $\mathrm{n}(\%)$ & $71(43.8 \%)$ & $101(57.1 \%)$ & 0.02 \\
\hline Back pain duration, (mean \pm SD) & $6.2 \pm 6.6$ & $9.3 \pm 8.0$ & $<0.001$ \\
\hline HLA-B27 positivity, n (\%) & $90(55.6 \%)$ & $36(20.3 \%)$ & $<0.001$ \\
\hline Elevated CRP (>5 mg/l), n (\%) & $28(17.3 \%)$ & $16(9.2 \%)$ & 0.02 \\
\hline Good response to NSAIDs, $\mathrm{n}(\%)$ & $85(52.5 \%)$ & $85(48 \%)$ & 0.45 \\
\hline Peripheral arthritis, current, $n$ (\%) & $5(3.1 \%)$ & $4(2.3 \%)$ & 0.74 \\
\hline Enthesitis, current, n (\%) & $12(7.4 \%)$ & $13(7.3 \%)$ & 1.00 \\
\hline Psoriasis, ever, $\mathbf{n}(\%)$ & $13(8 \%)$ & $21(11.9 \%)$ & 0.28 \\
\hline Inflammatory bowel disease, ever, n (\%) & $2(1.2 \%)$ & $4(2.3 \%)$ & 0.69 \\
\hline Uveitis, ever, n (\%) & $14(8.6 \%)$ & $9(5.1 \%)$ & 0.20 \\
\hline Family history of SpA, n (\%) & $19(11.7 \%)$ & $21(11.9 \%)$ & 1.00 \\
\hline BASDAl, 0-10 (mean \pm SD) & $4.2 \pm 2.0$ & $4.2 \pm 1.8$ & 0.90 \\
\hline BASFI, 0-10 (mean \pm SD) & $2.5 \pm 2.2$ & $2.4 \pm 1.8$ & 0.87 \\
\hline Patient global $(0-10)$, mean \pm SD & $5.3 \pm 2.7$ & $4.8 \pm 2.5$ & 0.07 \\
\hline Physician global (0-10), mean \pm SD & $3.9 \pm 2.3$ & $2.5 \pm 2.2$ & $<0.001$ \\
\hline
\end{tabular}

*Mann-Whitney U-test or Fisher's exact test, whatever appropriate.

axSpA=axial spondyloarthritis; BASDAl=the Bath Ankylosing Spondylitis Disease Activity Index; $B A S F I=$ the Bath Ankylosing Spondylitis Functional Index; $C B P=$ chronic back pain;

$\mathrm{CRP}=\mathrm{C}$-reactive protein; $\mathrm{SD}=$ standard deviation.

Conclusions: The self-referral strategy resulted in the diagnosis of axSpA in $19 \%$ of the patients as compared to $37 \%$ with a referral done by a physician. However, the proportion of axSpA among self-referred patients was clearly higher than the expected $5 \%$ prevalence of axSpA in patients with CBP. The online self-referral tool can be used, therefore, in addition to a physician based referral program to improve the early diagnosis and to increase awareness of axSpA.
Acknowledgements: The OptiRef project was supported by an unrestricted research grant from Novartis.

Disclosure of Interest: None declared

DOI: 10.1136/annrheumdis-2018-eular.4695

\section{THU0231 DO DEGREE OF FAMILY RELATIONSHIP AND ETHNICITY IMPACT THE ASSOCIATION BETWEEN A POSITIVE FAMILY HISTORY FOR SPONDYLOARTHRITIS AND PRESENCE OF HLA-B27? RESULTS FROM THE WORLDWIDE ASAS COHORT}

M. van Lunteren ${ }^{1}$, A. Sepriano ${ }^{1,2}$, R. Landewé ${ }^{3,4}$, J. Sieper $^{5,6}$, M. Rudwaleit ${ }^{5,7}$, D. van der Heijde ${ }^{1}$, F.A. van Gaalen ${ }^{1} .{ }^{1}$ LUMC, Leiden, Netherlands: ${ }^{2}$ NOVA Medical School, Universidade Nova de Lisboa, Lisbon, Portugal, ${ }^{3} A R C$, Amsterdam; ${ }^{4}$ Zuyderland Hospital, Heerlen, Netherlands; ${ }^{5}$ Charité Campus Benjamin Franklin; ${ }^{6}$ German Rheumatism Research Centre, Berlin; ${ }^{7}$ Klinikum Bielefeld, Bielefeld, Germany

Background: The ASAS definition of a positive family history (PFH) of spondyloarthritis (SpA) consists of the following diseases in first (FDR)- or second-degree relatives (SDR): ankylosing spondylitis (AS), acute anterior uveitis (AAU), reactive arthritis (ReA), inflammatory bowel disease (IBD), and psoriasis. In two European cohorts (SPACE and DESIR) a PFH of AS and AAU, but not a PFH of ReA, IBD, and psoriasis, were associated with HLA-B27 carriership in patients suspected of $\operatorname{axSpA}{ }^{1}$. However, it is unknown what the role of the degree of family relationship or ethnicity is.

Objectives: To investigate the impact of the degree of family relationship and ethnicity on the association between the current ASAS definition of a PFH and the presence of HLA-B27 in an international cohort of patients suspected of axSpA.

Methods: Baseline data from patients suspected of axSpA in the worldwide ASAS cohort were analysed. Univariable analyses were performed. Each disease (AS, AAU, psoriasis, IBD, ReA) in a PFH according to ASAS expert opinion was a determinant in separate models with HLA-B27 carriership as outcome. Analyses were stratified for FDR, SDR, and self-reported ethnicities (white, Asian, and other). Analyses were repeated in multivariable models.

Results: In total, 594 patients suspected of axSpA were analysed. Patients had a mean age (SD) of 33.7 (11.7) years, $46 \%$ were male, had a mean symptom duration of 7.1 (9.0) years, had 3.5 (2.2) SpA features including HLA-B27 and imaging, $52 \%$ were HLA-B27 positive, $20 \%$ had sacroiliitis according to the $\mathrm{mNY}$ criteria, and $32 \%$ had active inflammation on MRI-SI. Sixty-two percent of the patients were diagnosed as axSpA and of these diagnosed patients $83 \%$ fulfilled the ASAS axSpA criteria. A PFH was reported by $23 \%$ of the patients; a PFH of AS was the most (15\%) and PFH of AAU (1\%) the least often reported family history among all patients. Any PFH was associated with HLA-B27 carriership in patients with a PFH in FDR, whites, and Asians but not in SDR. A PFH of AS was positively associated with HLA-B27 carriership in all subgroups (table 1). A $\mathrm{PFH}$ of $\mathrm{AAU}, \mathrm{ReA}, \mathrm{IBD}$, or psoriasis was never positively associated with HLAB27 carriership. In the multivariate analysis, similar results were found.

Abstract THU0231 - Table 1. Univariable associations between each disease of a positive family history and HLA-B27 carriership in chronic back pain patients suspected of axSpA included in the ASAS cohort $(n=594)$

\begin{tabular}{|c|c|c|c|c|}
\hline & $\begin{array}{c}\text { HLA-B27+ } \\
n=310\end{array}$ & $\begin{array}{c}\begin{array}{c}\text { HLA-B27- } \\
n=284\end{array} \\
\text { ( }\end{array}$ & OR $(95 \% \mathrm{Cl})$ & p-value \\
\hline \multicolumn{5}{|l|}{ Any positive family history } \\
\hline \multicolumn{5}{|c|}{ Stratified by degree of family relationship } \\
\hline First-degree relatives & 79 & 31 & $2.9(1.8-4.5)$ & $<0.001$ \\
\hline Only second-degree relatives & 15 & 10 & $1.7(0.7-3.8)$ & 0.212 \\
\hline \multicolumn{5}{|l|}{ Stratified by self-reported ethnicity } \\
\hline white & 54 & 26 & $2.3(1.4-3.9)$ & 0.001 \\
\hline Asian & 38 & 14 & $3.1(1.6-5.8)$ & 0.001 \\
\hline Other ethnicities* & 2 & 1 & $2.3(0.2-25.0)$ & 0.509 \\
\hline \multicolumn{5}{|c|}{ Family history of ankylosing spondylitis } \\
\hline \multicolumn{5}{|c|}{ Stratified by degree of family relationship } \\
\hline First-degree relatives & 61 & 9 & $7.8(3.8-16.0)$ & $<0.001$ \\
\hline Only second-degree relatives & 13 & 4 & $3.7(1.2-11.6)$ & 0.023 \\
\hline \multicolumn{5}{|l|}{ Stratified by self-reported ethnicity } \\
\hline white & 37 & 6 & $7.1(2.9-17.1)$ & $<0.001$ \\
\hline Asian & 35 & 7 & $5.7(2.5-13.2)$ & $<0.001$ \\
\hline Other ethnicities* & 2 & 0 & n.a. & n.a. \\
\hline
\end{tabular}

Conclusions: In the international ASAS cohort, a PFH of AS, but not of AAU, $\mathrm{ReA}$, IBD, or psoriasis, was associated with HLA-B27 carriership in both first- and second-degree of family members and self-reported white and Asian ethnicity in patients suspected of axSpA. These data, in combination with data from two European cohorts, show that a PFH of AS and possibly also a PFH of AAU could be valuable in the general practice or other low SpA prevalence settings for identifying patients who are HLA-B27 positive and therefore have an increased risk of axSpA. 